\title{
The Effect of Tamarind Leaves (tamarindus indica linn) and Acarbose on Body Weight in Rats Type 2 Diabetes Mellitus Model
}

\author{
* $1^{\text {st }}$ Devi Novia \\ Postgraduate Program of Nutrition \\ Sciences \\ Universitas Sebelas Maret \\ Surakarta, Indonesia \\ devi92novia@gmail.com
}

\author{
$2^{\text {nd }}$ Sugiarto \\ Department of Internas Disease \\ Faculty of Medicine \\ Universitas Sebelas Maret \\ Surakarta, Indonesia \\ giarto.sppd@yahoo.co.id
}

\author{
$3^{\text {rd }}$ Yulia Lanti Retno Dewi \\ Department of Nutrition Sciences \\ Faculty of Medicine \\ Universitas Sebelas Maret \\ Surakarta, Indonesia \\ yulialanti@live.com
}

\begin{abstract}
Diabetes mellitus is a disease that causes an increase in blood glucose so that glucose in the calories is difficult to enter the cell and glycogenolysis process occurs then continues to the process of gluconeogenesis so that the body lacks energy and unloads food reserves in the muscles and adipose which results in the occurrence of weight loss in people with T2DM. Antioxidants are needed, namely tamarind leaves to help glucose enter cells. This study used 30 wistar rats that were 8 weeks old and weighed 150-200 g. Rats were induced with STZ as much as $45 \mathrm{mg} / \mathrm{kg}$, then $\mathrm{Na}$ as much as $110 \mathrm{mg}$ / $\mathrm{kg}$. In this study, rats were grouped into 5 groups namely, KN groups which were DMT2 rats without treatment, KP group who were DMT2 rats given acarbose drugs by $1.8 \mathrm{mg} / \mathrm{KgBB} /$ day and Group P1, P3, P3 were given leaf treatment tamarind with a dose of 28.56 , and $112 \mathrm{mg} / 200 \mathrm{gr} /$ day for 14 days. All data were collected and analyzed using ANOVA and LSD post hoc with $p$ value $<0.05$. In fasting blood glucose, the mean of all groups of rats was $264.83 \pm 1.47$ and the mean of body weight of rats after STZ induction was $180 \pm 3.84$. After 7 days of treatment, the body weight of rats in the treatment of KP $(184.17 \pm 3.18), P 1(182.50 \pm 6.15), P 2(182.17 \pm 5.77)$, and P3 $(189.67) \pm 2.65)$ increased significantly, whereas in the $\mathrm{KN}$ group $(173.67 \pm 4.59)$ weight loss occurred in the DMT2 model rats. Giving extract of tamarind leaves in P3 is better than KP which is an acarbose drug. Provision of tamarind leaves for 7 days, in the treatment group P3 increased body weight of rats and treatments $P 1$ and $P 2$ increased body weight the same as the treatment group KP (acarbose).
\end{abstract}

Keywords - Tamarind Leaves, STZ, NA, Body Weight

\section{INTRODUCTION}

There are many antidiabetic drugs that function the same, especially for reducing blood glucose level [1]. As it is known that blood glucose levels in T2DM can be reduced through several mechanisms, one of which is by giving antioxidants and inhibition through enzyme activity. In previous studies, the extracts of the tamarind studied studied showed inhibition of the enzyme $\alpha$-glucosidase in the intestine and tamarind leaves have also been shown to contain flavonoids (Quecetine) and tannins [2].
Inhibition of the $\alpha$-glucosidase enzyme can delay the breakdown of carbohydrates in the intestine and will reduce the absorption of blood sugar. One of the antidiabetic drugs with the same function as tamarind leaves is glucobay (acarbose) [3]. Use of this drug will give effects such as bloating, stomach cramps, and diarrhea. Diabetics on average look for other alternatives for treatment besides drug consumption. In people with diabetes mellitus, unwanted weight loss will occur [4].

\section{MATERIAL AND METHOD}

This type of research is an experimental laboratory study using a pre-test and post-test control group design. The maintenance and care of experimental animals will be held at the CFNS Experimental Mouse House, Postgraduate School, Gajah Mada University Yogyakarta, Indonesia.

\section{A. Preparation of Tamatind Leaves}

Tamarind leaves used in this study were obtained from plantations managed by residents in Karanganyar Regency, Central Java. Tamarind leaves which are still green are cleaned and washed. Dried for 3 days, then dried using an oven at $40^{\circ} \mathrm{C}$ for 2 days ( 24 hours). After being dried it is then mashed to a powder which is then extracted using a maceration method with ethanol, water solvent, and diethyl which was adopted from research conducted [6].

\section{B. Animal Model Type 2 Diabetes Mellitus}

Rats used are male Wistar, aged 8-12 weeks with a weight of 150-200 gr. Rats were adapted for 7 days in a cage with a room temperature of $270 \mathrm{C}$ and with lighting conditions 12 hours of bright cycles and 12 hours of dark cycles, as well as feeding and drinking water ad libitum. After adaptation, rats were induced by STZ (45 mg / kg) and $\mathrm{Na}(110 \mathrm{mg} / \mathrm{kg})$ for 3 days to get rats with hyperglycemia. All steps in this study were approved by the Health Research Ethics Committee, Faculty of Health, Sebelas Maret University with protocol number 474 / UNS27.06 / KEPK / EC / 2019; accepted on November 1, 2019. 


\section{Rats Groups}

After the type 2 diabetes mellitus model animal is formed, 30 rats were grouped into 5 groups namely $\mathrm{KN}$, KP, $\mathrm{P} 1-3$. The $\mathrm{KN}$ group was diabetic rats that were only given a standard diet, KP was diabetic rats given acarbose drugs by $1.8 \mathrm{mg} / 200 \mathrm{gr} / \mathrm{day}$, and P1-3 were diabetic rats given 28, $56,112 \mathrm{mg} / 200 \mathrm{gr} /$ day treatment . All diabetic mellitus rats were given a standard diet namely ADII and ad libitum drinks for 7 days.

\section{Statistical Analysis}

After the data is collected, the data is tested for normality. If the data are normal, proceed with the data homogeneity test (Levene's Test) with a value of $\mathrm{p}>0.05$. Followed by the One-Way Anova parametric statistical test then continued the Post Hock test with Tuckey High Significant Difference (HSD) if the data is normally distributed.

\section{RESULT}

Before the study began, initial weight condition in the five groups was compared to determine the homogeneity of the rats.

TABLE I. Average Body Weight Of Rats Before The Study

\begin{tabular}{|c|c|c|c|}
\hline Variable & Group & Mean \pm SD & $\mathbf{p}$ \\
\hline \multirow[t]{5}{*}{ BB (gr) } & $\mathrm{KN}$ & $184.3 \pm 3.67$ & 0.12 \\
\hline & KP & $183.33 \pm 3.07$ & \\
\hline & P1 & $184.33 \pm 5.16$ & \\
\hline & P2 & $181.83 \pm 4.66$ & \\
\hline & P3 & $188.0 \pm 2.28$ & \\
\hline
\end{tabular}

$\mathrm{KN}=$ Rats T2DM; KP = Rat T2DM + acarbose $1.8 \mathrm{mg} /$ $200 \mathrm{gr} /$ day; $\mathrm{P} 1=$ Rats $\mathrm{T} 2 \mathrm{DM}+$ tamarind leaf extract 28 mg / 200gr / day; P2 = Rats T2DM + tamarind leaf extract $56 \mathrm{mg} / 200 \mathrm{gr} /$ day; P3 = Rats T2DM + tamarind leaf extract $112 \mathrm{mg} / 200 \mathrm{gr} /$ day.

From the table 1, it can be seen that the body weight of homogeneous rats with $p>0.05$ which means there is no significant difference. Differences in average body weight of rats after administration of tamarind leaves in the 5 groups were known by the One-way anova test which had two variants namely the dose and duration of administration which can be seen in Table 2 .

TABLE II. EFFECT OF DOSE AND DURATION OF TAMARIND LEAF EXTRACT ON RATS WEIGHT

\begin{tabular}{|c|c|c|c|c|}
\hline \multirow{2}{*}{ DOSE } & \multicolumn{4}{|c|}{ DURATION } \\
\hline & $\mathbf{0}$ & 7 & 14 & $\mathbf{P}$ \\
\hline $\mathrm{KN}$ & $180 \pm 3.84$ & $173.66 \pm 4.58$ & $168 \pm 5.44$ & 0.002 \\
\hline $\mathrm{KP}$ & $179.16 \pm 2.92$ & $184.16 \pm 3.18$ & $192 \pm 2.68$ & $<0.001$ \\
\hline P1 & $179.50 \pm 6.37$ & $182.50 \pm 6.15$ & $186.16 \pm 6.33$ & 0.218 \\
\hline $\mathrm{P} 2$ & $176.83 \pm 4.57$ & $182.16 \pm 5.77$ & $189.00 \pm 5.89$ & 0.005 \\
\hline P3 & $184.33 \pm 2.80$ & $189.66 \pm 2.65$ & $197.66 \pm 3.01$ & $<0.001$ \\
\hline
\end{tabular}

$\overline{\mathrm{KN}}=$ Rats T2DM; KP = Rat T2DM + acarbose $1.8 \mathrm{mg} /$ 200gr / day; P1 = Rats T2DM + tamarind leaf extract 28 mg / 200gr / day; P2 = Rats T2DM + tamarind leaf extract $56 \mathrm{mg} / 200 \mathrm{gr} /$ day; $\mathrm{P} 3=$ Rats $\mathrm{T} 2 \mathrm{DM}+$ tamarind leaf extract $112 \mathrm{mg} / 200 \mathrm{gr} / \mathrm{day}$.

Based on the table, it is known that of the 5 groups and dosage treatments, duration of administration, as well as dose and duration of administration 4 of them had a mean significant difference $(p<0.05)$. In group $\mathrm{P} 1$ there were no significant differences. To find out the effect of dosage and duration of administration of tamarind leaf extract in each group, it can be seen in the table 3 .

TABLE III. EFFECT OF DOSE AND DURATION OF TAMARIND LEAF EXTRACT ON BODY WEIGHT IN EACH GROUP

\begin{tabular}{ccccc}
\hline DOSE & $\begin{array}{c}\Delta \text { (gr) } 7 \\
\text { hari }\end{array}$ & $\mathrm{p}$ & $\begin{array}{c}\Delta(\mathrm{gr}) \\
14 \\
\text { hari }\end{array}$ & $\mathrm{p}$ \\
\cline { 3 - 5 } $\mathrm{KN}: \mathrm{KP}$ & $-10.50^{*}$ & 0.005 & $-24.00^{*}$ & $<0.001$ \\
$\mathrm{KN}: \mathrm{P} 1$ & $-8.83^{*}$ & 0.024 & $-18.16^{*}$ & $<0.001$ \\
$\mathrm{KN}: \mathrm{P} 2$ & $-8.50^{*}$ & 0.032 & $-21.00^{*}$ & $<0.001$ \\
$\mathrm{KN}: \mathrm{P} 3$ & $-16.00^{*}$ & $<0.001$ & $-29.66^{*}$ & $<0.001$ \\
$\mathrm{KP}: \mathrm{P} 1$ & 1.66 & 0.97 & 5.83 & $<0.27$ \\
$\mathrm{KP}: \mathrm{P} 2$ & 2.00 & 0.94 & 3.00 & $<0.82$ \\
$\mathrm{KP}: \mathrm{P} 3$ & -5.50 & 0.27 & -5.66 & $<0.29$ \\
$\mathrm{P} 1: \mathrm{P} 2$ & 0.33 & 1.00 & -2.83 & $<0.85$ \\
$\mathrm{P} 1: \mathrm{P} 3$ & -7.16 & 0.09 & $-11.50^{*}$ & 0.004 \\
$\mathrm{P} 2: \mathrm{P} 3$ & -7.50 & 0.07 & $-8.66^{*}$ & 0.03 \\
\hline
\end{tabular}

$\mathrm{KN}=$ Rats $\mathrm{T} 2 \mathrm{DM} ; \mathrm{KP}=$ Rat $\mathrm{T} 2 \mathrm{DM}+$ acarbose $1.8 \mathrm{mg} /$ 200gr / day; P1 = Rats T2DM + tamarind leaf extract 28 $\mathrm{mg} /$ 200gr / day; P2 = Rats T2DM + tamarind leaf extract $56 \mathrm{mg} / 200 \mathrm{gr} /$ day; P3 = Rats T2DM + tamarind leaf extract $112 \mathrm{mg} / 200 \mathrm{gr} /$ day *) Showing significant differences $(\mathrm{p}<0,05)$.

After 7 days and 14 days of treatment, the KP-P3 group experienced a weight increase but in the KP group, P1, P2 and P3 had the same average weight and statistically the average group of the KP, P1, P2 and P3 was the same (p> 0.05). Weight loss in group P3 in table 3 increases higher than in the acarbose group (KP) or groups P1 and P2. The results of the interaction of two factors between dose and length of time it was found that the average body weight of rats was a significant difference $(\mathrm{p}<0.05)$.

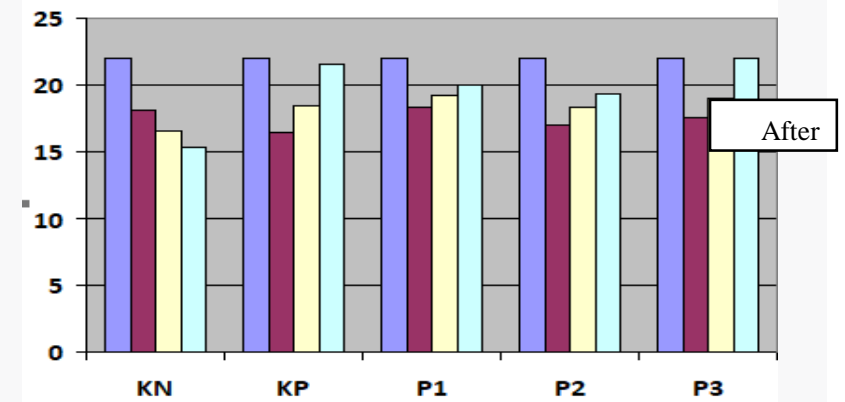

Fig. 1. Feed Intake Rats

Blue: after adaptation; Red: 0 days; Cream: 7 day; Green: 14 day; $\mathrm{KN}=$ Rats T2DM; KP = Rat T2DM + acarbose $1.8 \mathrm{mg} / 200 \mathrm{gr} /$ day; P1 = Rats T2DM + tamarind leaf extract $28 \mathrm{mg} / 200 \mathrm{gr} /$ day; P2 = Rats T2DM + tamarind leaf extract $56 \mathrm{mg} / 200 \mathrm{gr} /$ day; P3 = Rats T2DM + tamarind leaf extract $112 \mathrm{mg} / 200 \mathrm{gr} /$ day

Figure 1 shows that the feed intake of rats after good adaptation is 22 grams in each group. After being Na-STZinduced rat feed decreased. In the $\mathrm{KN}$ group, rat feed 
continuously decreased until the end of the study. Whereas in the groups of KP, P1, P2, and P3 feed consumption in rats continued to increase. The highest increase and return to normal feed occurred in group P3 on day 14.

\section{DISCUSSION}

STZ cause by destruction of pancreatic beta cells which causes DNA fragmentation through DNA acylation, resulting in changes in DNA of pancreatic beta cells. STZ causes inhibition in the Krebs cycle which can decrease mitochondrial oxygen. This effect reduces ATP in pancreatic beta cells and limits the production of mitochondrial ATP which causes hyperglycemia conditions by blocking the secretion and synthesis of insulin [7]. STZ is a toxic material that can increase oxidative stress, endothelial dysfunction, and trade so that $\mathrm{Na}$ is needed to protect excess damage to tissue type 2 diabetes mellitus rats [8].

From the results of the study note that the administration of tamarind leaf extract of $112 \mathrm{mg} / 200 \mathrm{gr} /$ day was significantly more significant in increasing body weight compared to the drug Acarbose although seen from the increase in feed consumption the acrbose drug group equaled the highest dose of tamarind leaf extract group. Based on Figure 1 it is known that administration of tamarind leaf extract for 7-14 days increases the consumption of rat feed both in the short and long term and can exceed the acarbose group.

Research conducted by [9], states that in DM insulin deficiency will occur which results in disruption of protein and fat metabolism which causes weight loss and reduced amount of calorie storage. Some studies state that the relationship between body weight and fasting blood sugar due to insulin is known as a glucose absorption receptor through a special membrane of insulin which increases blood glucose levels due to delayed glucose uptake. If the body is unable to get enough energy from sugar, the body will process other substances to be converted into energy such as fats and proteins that cause weight loss [10].

\section{CONCLUSION}

It was found that tamarind leaf extract by giving for 7 days in rats with type 2 diabetes mellitus can increase insulin levels and can reduce insulin resistance through Homa-IR calculation at a dose of $112 \mathrm{mg} / \mathrm{KgBW} /$ day. Therefore, the extract of tamarind can be introduced in the literature and alternative herbal medicine in the treatment of type 2 diabetes mellitus.

\section{ACKNOWLEDGMENT}

We really appreciate and thank Mr. Yulianto, staff of the food laboratory and nutrition study center, gadjah mada university for their hard work and guidance in maintaining and testing samples during this study.

\section{REFERENCES}

[1] Yang N., Sampathkumar K., dan Loo SCJ. Recent Advances in Complementary and Replacement Therapy with Nutraceuticals in Combating Gastrointestinal Illnesses. Clinical Nutrition journal, vol.36, no.4. 2017.

[2] Sultan MT, Butt MS, Karim R, et al. Effect of Nigella Sativa Fixed and Essential Oils on Antioxidant Status, Hepatic Enzymes and Immunity in Streptozotocin Induced Diabetes Mellitus. BMC Complement Altern Med. DOI:10. 1186 /1472 -6882 -14 -193. PMID : 24 939518. 2014.

[3] Escalona-Arranz, J. C., Perez-Rosés, R., Rodríguez- Amado, J., Morris-Quevedo, H. J., Mwasi, L. B., Cabrera-Sotomayor, O., Puente-Zapata, E. Antioxidant and toxicological evaluation of aTamarindus indicaL. leaf fluid extract. Natural Product Research, vol.30, no.4 DOI: 10.1080/14786419.2015.1019350. 2015.

[4] Yuniarti Elsa, Putri Dwi Hilda, Syamsurizal Yuni Ahda Puja Delfi Sonata. Correlation Of Fasting Blood Glucose With Il-6 Levels In Type 2 Diabetes Mellitus Ethnic Minangkabau. Bioscience. Volume 2 Number 1,pp. 11-21. 2018.

[5] Tahrani AA., Bailey CJ., Prato SD., dan Barnett AH. Management of type 2 diabetes: new and future developments in treatment. Lancet, vol.378. 2011

[6] Singh, S., Usman, K., dan Banerjee, M. Pharmacogenetic Studies Update in Type 2 Diabetes Mellitus. World Journal of Diabetes, vol.7, no. 15 , hlm. 302-315. 2016

[7] Rahul Chandrana, Thangaraj Parimelazhagana, and Saravanan Shanmugam. Antidiabetic activity of Syzygium calophyllifolium in Streptozotocin- Nicotinamide induced Type-2 diabetic rats. Biomedicine and Pharmacotherapy journal. 2016.

[8] Ghasemi A., Khalifi S., dan Jedi S. Streptozotocin-NicotinamideInduced Rat Model Of Type 2 Diabetes. Journal of Diabetes and Metabolic Disorders, vol.12. 2014.

[9] Yohanes Andy Rias, Ekawati Sutikno. Hubungan Antara Berat Badan Dengan Kadar Gula Darah Acak Pada Tikus Diabetes Mellitus. Jurnal Wiyata, Vol. 4 No. 1. 2017.

[10] Kelley, D. E., Kuller, L. H., McKolanis, T. M., Harper, P., Mancino, J., \& Kalhan, S. Effects of moderate weight loss and orlistat on insulin resistance, regional adiposity, and fatty acids in type 2 diabetes. Diabetes Care, 27(1), 33-40. 2004. 